\title{
VULVAR MYIASIS- A CASE REPORT
}

\author{
Archana Kumari' ${ }^{1}$ Suman Kumari²
}

${ }^{1}$ Associate Professor, Department of Obstetrics and Gynaecology, RIMS, Ranchi.

${ }^{2} 3^{\text {rd }}$ Year Junior Resident, Department of Obstetrics and Gynaecology, RIMS, Ranchi.

HOW TO CITE THIS ARTICLE: Kumari A, Kumari S. Vulvar myiasis- a case report. J. Evolution Med. Dent. Sci. 2018;7(04):544-545, DOI: $10.14260 /$ jemds/2018/121

\section{CASE PRESENTATION}

A 19-year-old young married woman presented on day 6 of postnatal period with chief complaints of pain at the episiotomy site since 1 day. The pain was severe, continuous in nature and associated with crawling sensation in the genital area. She lived in rural area with conditions of poor hygiene. She underwent a vaginal delivery 6 days back in local district hospital. Her immediate postnatal period was uneventful. She gave history of using homemade sanitary pads in the postnatal period. General and physical examination revealed no abnormalities. On local examination, there was gaping of episiotomy wound (Fig. 1). There were numerous maggots in the wound. Rest of the genitalia was unremarkable. The patient was admitted for further management.

\section{PATHOLOGICAL DISCUSSION}

Myiasis is a zoonosis resulting from an infestation by the larvae of flying dipterous insects. The name of the condition is derived from an ancient Greek Word uvia (myia) meaning fly. The term was first introduced by Hope in 1840. Myiasis is a zoonosis resulting from a parasitic infestation of the skin, mucosa, necrotic tissue or natural orifices or cavities of humans or animals by larvae or pupa of several fly species to complete partial or total development of their evolutive cycle.[1] Vulvar myiasis is a rare entity and constitutes only $0.7 \%$ of human infestation.[2] Myiasis can be classified according to site of infestation as mucocutaneous, ophthalmic, nasal, nasopharyngeal, intestinal or urinary tract myiasis. There are two forms of myiasis: Obligate in which the larvae feed themselves on living tissues and Facultative myiasis where the larvae opportunistically take advantages of wounds or degenerative necrotic conditions. [3] Chrysomya bezziana is the most common cause of cutaneous myiasis in India, but usually infests wounds and mucous membranes. ${ }^{[4]}$

Predisposing factors for human myiasis include open wounds, presence of bleeding and bad odour of decomposition, poor hygiene, open air defecation practices, advanced age, summer season, diabetes, physically challenged and debilitated person.[5] Subjects with immunecompromised states like HIV, HBsAg, syphilis and HCV are prone to myiasis. On evaluation of our patient revealed that she had low educational status, lived in rural area, in conditions of poor hygiene and use of non-hygienic toilet lead

'Financial or Other Competing Interest': None.

Submission 13-12-2017, Peer Review 06-01-2018,

Acceptance 13-01-2018, Published 22-01-2018.

Corresponding Author:

Dr. Archana Kumari,

House No. 16, Annapurna Enclave,

Maitri Marg, Bariatu Housing Colony,

Bariatu, Ranchi-834009.

E-mail: dr_karchana@yahoo.co.in

DOI: $10.14260 /$ jemds $/ 2018 / 121$ to infestation of large number of flies. The washed undergarments and homemade sanitary pads, which she used were dried and kept open on which flies may lay their eggs. Hence, in our patient the possible cause of vulvar myiasis is poor hygiene, as all the other causes were ruled out. The clinical manifestations of myiasis depend upon the affected body part and the extent of infestation. Patient may have complaints of pain, fever, bleeding from infested site, pruritus and they often have the sense of something moving under the skin. The prognosis is generally good, treatment consists of removal of the parasitic larvae and thorough cleaning of affected area and treat any secondary bacterial infection. As poor hygiene is known to be associated with vulvar myiasis, washing and keeping the genital area clean may prevent to a great extent the occurrence of this condition. Baidya has reported a case of genital myiasis in women with genital prolapse and malignancy.[6] Passos et al reported a case of vulvar myiasis during pregnancy.[7] Singhal et al reported a case of vulvar myiasis in a 72-year-old female.[8]

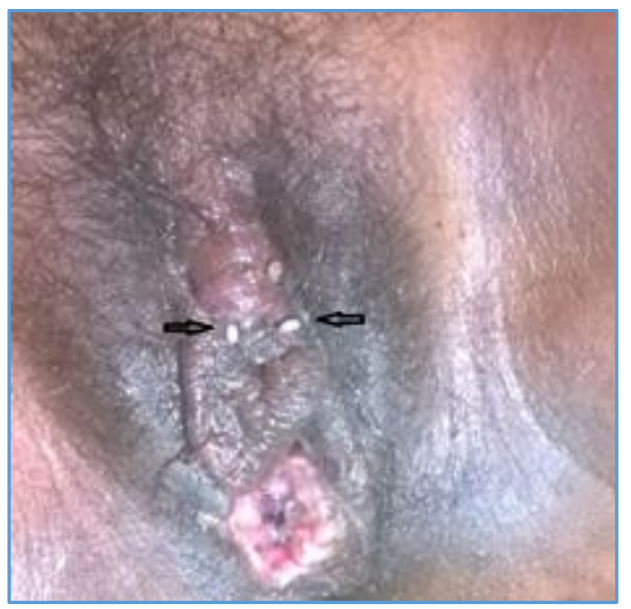

Figure 1. Episiotomy Wound Gaping with Maggots

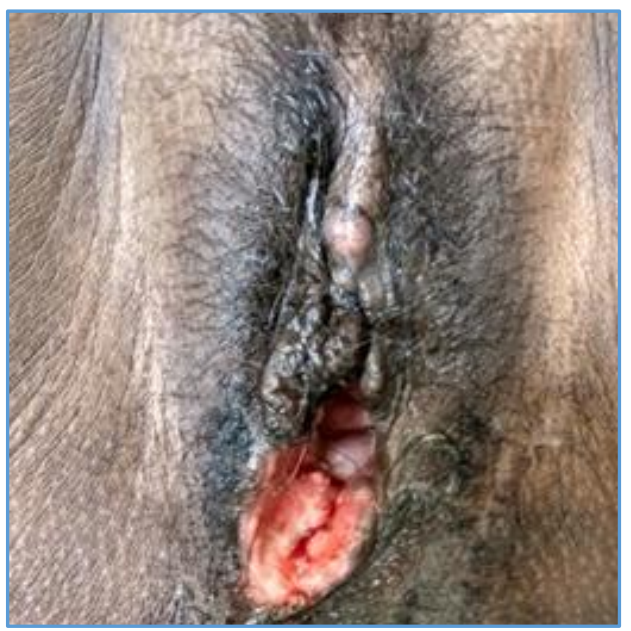

Figure 2. Episiotomy Wound after Removal of Maggots 


\section{DISCUSSION OF MANAGEMENT}

The treatment was started with antibiotics and analgesics. The larvae were removed manually with the help of forceps after application of turpentine oil-soaked bandage. This procedure drew out and killed the maggots burrowed deep into the wound as well as the maggots on the surface. The procedure was repeated twice daily and each time maggots were removed. After 2 days, the wound was free of maggots and patient's symptoms completely resolved after the extraction of maggots (Fig. 1,2). The patient was anaemic with haemoglobin of 8.2 gm\% and her HIV, HBsAg and VDRL tests were non-reactive. Her blood sugar level was within normal limits. Counselling of the patient was done regarding maintenance of perineal hygiene to avoid re-infestation. The patient was discharged after 4 days of hospital stay on oral antibiotics and analgesics and was under follow-up.

\section{CONCLUSION}

Vulvar myiasis is infestation of vulva with larvae and maggots. The location of myiasis at the genital region is a very rare occurrence. The predisposing factors for infestation by larvae are poor hygiene, debilitated person, bleeding or odours from decomposing tissues, summer season, immunedeficient conditions like HIV, HBsAg, etc. Patients should be thoroughly examined before treating them for the complaints. The treatment involves placement of normal saline soaked gauze with few drops of turpentine oil in the vulval area for few minutes. Subjects should be educated about safe sexual practices, personal hygiene and discouragement of open air defecation and use of sterile sanitary pads.

\section{REFERENCES}

[1] Garrido-Rios AA, Sanz-Munoz C, Miranda-Sivelo A, et al. Major depressive episode secondary to condylomata acuminata. Gen Hospital Psychiatry 2010;32(4):446.e3-5.

[2] Sherman RA. Wound myiasis in urban and suburban United States. Arch Intern Med 2000;160(13):200414.

[3] Burgess IF. Myiasis: maggots infestation. Nurs Times 2003;99(13):51-3.

[4] McGraw TA, Turiansky GW. Cutaneous myiasis. J Am Acad Dermatal 2008;58(6):907-26.

[5] Gomes PA, Fukugava MF, Cuce LC. Vulvar myiasis. J Bras Med 1996;70:106-8.

[6] Baidya J. A rare case of genital myiasis in a woman with genital prolapsed and malignancy and review of the literature. Ann Trop Med Public Health 2009;2(1):29-30.

[7] Passos MR, Varella RQ, Tavares RR, et al. Vulvar myiasis during pregnancy. Infect Dis Obstet Gynecol 2002;10(3):153-8.

[8] Singhal S, Bhugra P. Vulvar myiasis: a rare case report. Int J Case Rep \& Images 2015;6(2):108-10. 